\title{
The Impact of Illness Perceptions on Depressive Symptoms Among Benign Prostatic Hyperplasia Patients with Lower Urinary Tract Symptom
}

\author{
Linlin Yang ${ }^{1,2}$ \\ Xin Chen ${ }^{3}$ \\ Zhiqi Liu ${ }^{3}$ \\ Wei Sun ${ }^{3}$ \\ Dexin $\mathrm{Yu}^{3}$ \\ Haiqin Tang ${ }^{1,2, *}$ \\ Zhiqiang Zhang ${ }^{3, *}$ \\ 'Department of Geriatrics Cardiology, \\ The First Affiliated Hospital of Anhui \\ Medical University, Hefei, People's \\ Republic of China; ${ }^{2}$ Department of \\ General Medicine, The First Affiliated \\ Hospital of Anhui Medical University, \\ Hefei, People's Republic of China; \\ ${ }^{3}$ Department of Urology, The Second \\ Affiliated Hospital of Anhui Medical \\ University, Hefei, People's Republic of \\ China
}

*These authors contributed equally to this work

\begin{abstract}
Objective: This study aimed at exploring whether illness perceptions may mediate the relationship between depressive symptoms and lower urinary tract symptoms (LUTS) among benign prostatic hyperplasia (BPH) patients.

Methods: The Patient Health Questionnaire (PHQ-9) for depression, the International Prostate Symptom Score (IPSS) for the severity of LUTS and the brief Illness Perception Questionnaire (B-IPQ) for illness perceptions (IPs) were used among the $157 \mathrm{BPH}$ patients with LUTS. Pearson's correlation test and hierarchical regression analyses were used to assess the correlations between LUTS, depressive symptoms and IPs.

Results: Our study found that the severity of LUTS was associated with depressive symptoms and subscales of illness perception; meanwhile, IPs were associated with the level of education. A positive relationship was found between the scores of PHQ9 and the B-IPQ subscales of illness consequences, identity, timeline, concern and emotion; thus, a negative correlation was found between scores of PHQ9 and the B-IPQ subscales of illness coherence, personal control and treatment control. The hierarchical regression analysis showed IPSS and the B-IPQ subscales of illness consequences, concern and emotion were significantly associated with depression, and explained $85.1 \%$ of the variance in depressive symptoms $\left(\mathrm{R}^{2}=0.851, \mathrm{p}<0.05\right)$.

Conclusion: The relationship between LUTS and depressive symptoms may be mediated by the negative IPs, including consequences, concern and emotions. Clinicians should not only focus on the LUTS but also on the IPs to improve depressive symptoms among BPH patients.
\end{abstract}

Keywords: lower urinary tract symptom, illness perceptions, benign prostatic hyperplasia, depression

\section{Introduction}

$\mathrm{BPH}$ is one of the most common chronic conditions in older men, and typically presents with lower urinary tract symptoms. The incidence of BPH will markedly rise with progressive aging of the adult male, especially after 40 years old. ${ }^{1}$ LUTS comprise storage (frequency, urgency, and nocturia), voiding (poor stream, hesitancy, and straining to void) and post-micturition symptoms. ${ }^{2}$ Despite the fact that LUTS/BPH is not a life-threatening condition, the elderly who suffer LUTS often have many concomitant illnesses (eg constipation, neurological disease) ${ }^{3}$ and increase the risk for serious adverse events (eg falls, fractures), ${ }^{4}$ which have a significant impact on the quality of life. ${ }^{5}$ In addition, LUTS/BPH is associated
Department of Geriatrics Cardiology, The First Affiliated Hospital of Anhui Medical University, No. 218 Jixi Road, Hefei, Anhui, 230022, People's Republic of China Email tanghq_card@I26.com

Zhiqiang Zhang

Department of Urology, The Second Affiliated Hospital of Anhui Medical University, No. 678 Furong Road, Hefei, Anhui, 230032, People's Republic of China Email zhangzq_urology@126.com 
with many psychological conditions, including depression and anxiety. A nationwide population-based study demonstrated that depression is a major risk factor for the dementia in patients with LUTS, and early screening and interventions for depression in patients with LUTS may play an important role in maintaining cognitive function. ${ }^{6}$ In addition, Chiang et $\mathrm{al}^{7}$ demonstrated that LUTS increased the risk of dementia in Chinese population.

Depression is a highly prevalent condition, especially among older adults and cancer patients, ${ }^{8-10}$ which affects the quality-of-life of patients and increases burden of families and public health care costs. ${ }^{11}$ Increasing crosssectional studies have reported that BPH/LUTS was significantly associated with depressive symptoms. Men with LUTS were shown to be at 2.60 3.9 times higher risk of depression than those without LUTS. ${ }^{12-14}$

Despite the well-documented high incidence of depression in BPH patients, the mechanisms underpinning the psychological associations remain to be poorly understood. Leventhal et $\mathrm{al}^{15}$ first proposed the concept of illness perception and developed the Common Sense Model (CSM). According to the Common Sense Model of SelfRegulation, when faced with threats to health, individuals generate cognitive, emotional, and causal cognitions and the beliefs about the illness. These cognitions and the beliefs about the condition of the illness originate from past knowledge and experiences, and information from others (eg media, doctors). IPs, as a fundamental component of CSM, consist of five dimensions, including identity, causes, consequences, timeline, control (personal control and treatment control), and emotional dimensions. Increasing studies have investigated the relationship between IPs and the health-related quality of life (HRQOL)/psychological distress in cancer and noncancer populations. Shallcross et $\mathrm{al}^{16}$ found that IPs mediate the relationship between depression and quality of life in patients with epilepsy. A study by De Gucht ${ }^{17}$ demonstrated that IPs mediate the relationship between bowel symptom severity and HRQOL in irritable bowel syndrome patients.

From the previous studies, IPs are potentially important determinants of psychological distress, the present study first aimed at exploring the following hypotheses: (1) We examined the severity of depressive symptoms and IPs in BPH patients with LUTS. (2) The current study aimed at exploring whether IPs may mediate the hypothesized relationship between depressive symptoms and LUTS among BPH patients.

\section{Materials and Methods}

\section{Participants}

Patients with a diagnosis of BPH were recruited to the Second Affiliated Hospital of Anhui Medical University from May 2016 to December 2018. In current study, the eligibility criteria are as follows: (1) Chinese-speaking; (2) no psychological distress; (3) age $>60$ years old; (4) diagnosis of BPH.

The following exclusion criteria included: (1) clinical evidence of prostate cancer; (2) prostate-specific antigen (PSA) $>10 \mathrm{ng} / \mathrm{mL}$, (4) malignant tumors; (5) diagnosis of neurological or psychiatric disease; (6) with serious comorbidities (including diabetes mellitus); (7) taking any drugs for BPH (eg, alpha-blockers, 5areductase inhibitor).

\section{Materials}

The aims and procedures of the present study were explained to each participant, and we conducted face-toface interviews.

\section{Socio-Demographic and Clinical Characteristics}

Socio-demographic data were gathered from medical records and socio-demographic questionnaire (eg age, marital status, level of education). Clinical characteristics, including disease-specific information (prostatic volume, PSA), time since diagnosis and treatment of $\mathrm{BPH}$, were collected from medical records and patients.

\section{The International Prostate Symptom Score (IPSS)}

The first version of IPSS is designed to assess the BPHrelated symptoms in 1992 by the American Urological Association (AUA). IPSS is a quick self-administered tool, which is widely used to evaluate LUTS in men with urinary complaints. ${ }^{18}$ The IPSS consists of seven questions regarding symptoms (frequency, urgency, nocturia, intermittency, weak urine stream and straining) and one LUTSspecific question on HRQoL. ${ }^{19}$ The total scores of symptoms range from 0 to 35 . For the symptom score, scores ranging from 1 to 7 indicate mild symptom, scores ranging from 8 to 19 indicate moderate symptoms, scores ranging from 20 to 35 indicate severe symptoms. The Chinese version of IPSS had good content validity and reliability. ${ }^{20}$ In our study, LUTS were measured with the Chinese version of IPSS.

The Brief Illness Perception Questionnaire (B-IPQ) IPs in BPH patients with LUTS were assessed with the Chinese version of the 8-item B-IPQ. The B-IPQ was used 
to evaluate cognitive and emotional characteristics of illness among the patients with BPH. The B-IPQ had good reliability and validity, which was widely used among different populations. ${ }^{21,22}$ Each core item has a 0-10point scale. The B-IPQ was designed to assess consequences (how much influence of the illness on their life), timeline (how long the prospects of illness duration will continue), identity ("experienced symptoms of illness"), personal control ("the individual beliefs of control over the illness"), treatment control ("the individual beliefs in treatment"), coherence (understanding of illness), concern ("the extent of concern about illness") and emotion (emotional response to illness). ${ }^{21,23,24}$

\section{The Patient Health Questionnaire (PHQ-9)}

Depression was assessed by the Chinese version of the Patient Health Questionnaire (PHQ-9) in BPH patients. PHQ-9 is developed on a self-assessment scale designed to rapidly and reliably assess symptoms of depression based on symptoms over a two-week period. ${ }^{25}$ The PHQ9 , as a valid and reliable questionnaire, has a good internal consistency (Cronbach's alpha $=0.86$ ) in China. ${ }^{26}$ PHQ-9 contains 9 items, which are assessed on a 4-point scale according to the frequency. The total scores for PHQ-9 ranges from 0 to 27 . The severity of depressive symptoms depends on the total score, and higher scores indicate greater level of depressive symptoms. The scores ranging from 0 to 4 indicate no depressive symptom, scores ranging from 5 to 9 represent with mild depressive symptoms, scores ranging from 10 to 14 represent with moderate depression symptoms, scores ranging from 15 to 19 represent with moderately severe depression symptoms, scores ranging from 20 to 27 represent with severe depression symptoms. ${ }^{27}$

\section{Statistical Analysis}

Our data analysis was calculated using SPSS 24.0 (SPSS Inc., Chicago, IL, USA). An analysis of variance (ANOVA) was conducted to compare continuous variables, and a chi-square test was conducted to compare categorical variables among different groups. Pearson's correlations were conducted to assess relationships between LUTS, depressive symptoms, and illness perceptions and correlations between B-IPQ subscales. In order to determine the independent contribution of variance to depressive symptoms, the hierarchical regression analyses were conducted. A p-value $<0.05$ was considered to be statistically significant.

\section{Results}

\section{Sociodemographic and Disease-Specific}

\section{Characteristics}

A total of 157 BPH patients (from Hefei city) with LUTS were approached for participation. The mean age was 68.65 years $(\mathrm{SD}=5.33)$, the majority of participants in our sample were married $(\mathrm{n}=152 ; 96.8 \%), 60.5 \%(95 /$ 157) had primary education. The mean BMI was 23.36 $\mathrm{Kg} / \mathrm{m}^{2}$ ( $\mathrm{SD}=2.88$ ). Overall, $13.4 \%$ were current smokers, $12.1 \%$ were non-drinkers. The mean PSA was $2.80 \mathrm{ng} / \mathrm{mL}$ $(\mathrm{SD}=1.26)$, and the mean PV was $66.60 \mathrm{~mL}$ (32.72). The majority of the patients $(\mathrm{n}=142 ; 90.5 \%)$ had moderate LUTS for analysis, and only 12 patients (7.6\%) presented severe LUTS (see Table 1).

\section{IPs and Depressive Symptoms Among BPH Patients with LUTS}

Table 2 shows that non-depression, mild and moderate depression groups differ in LUTS and IPs. Table 3 shows

Table I Socio-Demographic and Clinical Characteristics of All participants $(\mathrm{N}=157)$

\begin{tabular}{|c|c|c|c|}
\hline Variable & $\mathbf{N}$ & $\%$ & $\begin{array}{l}\text { Mean } \pm \text { SD/Median } \\
\text { (Range) }\end{array}$ \\
\hline Age (years) & & & $68.65 \pm 5.33$ \\
\hline $\mathrm{BMI}\left(\mathrm{Kg} / \mathrm{m}^{2}\right)$ & & & $23.36 \pm 2.88$ \\
\hline Current smoker & 21 & 13.4 & \\
\hline Alcohol use & 19 & 12.1 & \\
\hline $\begin{array}{l}\text { Educational status } \\
\text { Primary education } \\
\text { High school } \\
\text { Higher education }\end{array}$ & $\begin{array}{l}95 \\
51 \\
11\end{array}$ & $\begin{array}{l}60.5 \\
32.5 \\
7.0\end{array}$ & \\
\hline $\begin{array}{l}\text { Marital status } \\
\text { Married } \\
\text { Divorced/Widowed }\end{array}$ & $\begin{array}{l}152 \\
5\end{array}$ & $\begin{array}{l}96.8 \\
3.2\end{array}$ & \\
\hline PSA (ng/mL) & & & $2.80 \pm 1.26$ \\
\hline Prostate volume $(\mathrm{mL})$ & & & $66.60 \pm 32.72$ \\
\hline $\begin{array}{l}\text { Lower urinary tract } \\
\text { symptoms } \\
\text { None }(0) \\
\text { Mild }(1-7) \\
\text { Moderate }(8-19) \\
\text { Severe }(20-35)\end{array}$ & $\begin{array}{l}0 \\
3 \\
142 \\
12\end{array}$ & $\begin{array}{l}1.9 \\
90.5 \\
7.6\end{array}$ & \\
\hline $\begin{array}{l}\text { Duration of LUTS } \\
\text { (month) }\end{array}$ & & & $|5.56 \pm 4.0|$ \\
\hline
\end{tabular}


Table 2 Comparison of LUTS and IPs Between Different BPH Patients with Depressive Symptoms

\begin{tabular}{|c|c|c|c|c|c|}
\hline Variable & Non-Depression $(n=\mid 27)$ & Mild Depression $(n=26)$ & Moderate Depression $(n=4)$ & $F / x^{2}$ & $\mathbf{P}$ \\
\hline Age (years) & $68.39 \pm 5.35$ & $69.23 \pm 5.20$ & $73.25 \pm 3.77$ & 1.821 & 0.165 \\
\hline $\operatorname{BMI}\left(\mathrm{Kg} / \mathrm{m}^{2}\right)$ & $23.45 \pm 2.95$ & $22.67 \pm 2.60$ & $24.93 \pm 1.68$ & 1.393 & 0.252 \\
\hline Current smoker & 16 & 5 & 0 & 1.118 & 0.553 \\
\hline Alcohol use & 14 & 4 & I & 1.796 & 0.362 \\
\hline Educational status & & & & 6.045 & 0.151 \\
\hline Primary education & 71 & 21 & 3 & & \\
\hline High school & 45 & 5 & I & & \\
\hline Higher education & 11 & 0 & 0 & & \\
\hline Marital status & & & & 1.002 & 0.640 \\
\hline Married & 122 & 26 & 4 & & \\
\hline Divorced/Widowed & 5 & 0 & 0 & & \\
\hline PSA (ng/mL) & $2.75 \pm 1.26$ & $3.15 \pm 1.17$ & $2.16 \pm 1.09$ & 1.645 & 0.196 \\
\hline Prostate volume $(\mathrm{mL})$ & $67.54 \pm 33.79$ & $63.89 \pm 29.67$ & $54.40 \pm 9.57$ & 0.417 & 0.660 \\
\hline LUTS (IPSS) & $13.35 \pm 3.17$ & $16.46 \pm 4.15$ & $18.75 \pm 5.12$ & 13.022 & $0.000 *$ \\
\hline Duration of LUTS (month) & $14.59 \pm 3.47$ & $19.08 \pm 3.33$ & $23.50 \pm 2.38$ & 29.396 & $0.000 *$ \\
\hline \multicolumn{6}{|l|}{ Illness perception } \\
\hline Consequences & $3.79 \pm 1.09$ & $6.30 \pm 0.74$ & $8.50 \pm 1.29$ & 94.449 & $0.000 *$ \\
\hline Timeline & $3.65 \pm 0.86$ & $5.19 \pm 1.06$ & $6.00 \pm 0.00$ & 43.376 & $0.000 *$ \\
\hline Personal control & $3.83 \pm 0.99$ & $2.57 \pm 0.81$ & $2.00 \pm 0.00$ & 24.038 & $0.000 *$ \\
\hline Treatment control & $4.91 \pm 1.05$ & $3.00 \pm 0.63$ & $2.25 \pm 0.50$ & 51.227 & $0.000 *$ \\
\hline Identity & $3.56 \pm 1.12$ & $5.88 \pm 0.51$ & $7.25 \pm 0.95$ & 73.466 & $0.000 *$ \\
\hline Concern & $3.89 \pm 0.90$ & $6.27 \pm 0.53$ & $8.25 \pm 0.50$ & 125.775 & $0.000 *$ \\
\hline Coherence & $4.24 \pm 1.00$ & $2.84 \pm 0.88$ & $1.75 \pm 0.50$ & 32.809 & $0.000 *$ \\
\hline Emotions & $3.56 \pm 0.99$ & $6.04 \pm 0.60$ & $8.00 \pm 0.82$ & II2.204 & $0.000 *$ \\
\hline Total score of IP & $31.45 \pm 2.68$ & $38.11 \pm 1.63$ & $44.00 \pm 2.83$ & 113.662 & $0.000 *$ \\
\hline
\end{tabular}

Note: $*$ P $<0.001$ (2-tailed).

Abbreviations: LUTS, lower urinary tract symptoms; IPs, illness perceptions.

the mild, moderate and severe LUTS groups differ in severity of depression and IPs. We analyzed the B-IPQ scores for every item. Intercorrelations between Chinese B-IPQ subscales are presented in Table 4. The analysis showed good intercorrelations among items. The results suggested that the BPH patients with LUTS perceiving more labels and symptoms (consequences and identity) reported longer illness duration, less personal and treatment control, more concern, and had more negative emotional impact. Our results showed a positive correlation between depression scores and the scores on the B-IPQ subscales of consequences $(r=0.875)$, timeline $(r=0.668)$, identity $(r=0.779)$, concern $(r=0.871)$, emotions $(\mathrm{r}=0.878)(p<0.001)$. There was a negative correlation between the depression scores and the scores on the B-IPQ subscales of person control $(\mathrm{r}=-0.647)$, treatment control $(r=-0.715)$ and coherence $(r=-0.701)(p<0.001)$.
There was a positive correlation between LUTS and negative IPs included consequences $(r=0.528)$, timeline $(r=0.417)$, identity $(r=0.457)$, concern $(r=0.479)$, emotions $(r=0.512)$ $(p<0.001)$. Thus, there was a negative association between LUTS and positive IPs, including person control $(r=$ $-0.464)$, treatment control $(\mathrm{r}=-0.473)$ and coherence $(\mathrm{r}=$ $-0.525)(p<0.001)$ (See Table 5).

There was a very weak negative correlation between the depressive symptoms and the level of education $(\mathrm{r}=-0.339)$ $(p<0.001)$. Results showed that the level of education was negatively associated with negative IPs included consequences $(r=-0.400)$, timeline $(r=-0.282)$, identity $(r=$ $-0.241)$, emotions $(r=-0.304)(p<0.001)$, but positively associated with positive IPs included personal control $(\mathrm{r}=$ 0.299), treatment control $(r=0.271)$ and illness coherence $(r=0.497)(p<0.01)($ See Table 6). 
Table 3 Comparison of Depressive Symptoms and IPs Between Different BPH Patients with LUTS

\begin{tabular}{|c|c|c|c|c|c|}
\hline Variable & Mild LUTS (n=3) & Moderate LUTS $(n=\mid 42)$ & Severe LUTS $(n=\mid 2)$ & $F / x^{2}$ & $\mathbf{P}$ \\
\hline Age (years) & $66.67 \pm 1.53$ & $68.43 \pm 5.34$ & $71.75 \pm 4.92$ & 2.405 & 0.094 \\
\hline $\operatorname{BMI}\left(\mathrm{Kg} / \mathrm{m}^{2}\right)$ & $25.17 \pm 4.23$ & $23.29 \pm 2.89$ & $23.72 \pm 2.63$ & 0.720 & 0.488 \\
\hline Current smoker & 1 & 17 & 3 & 3.476 & 0.145 \\
\hline Alcohol use & 0 & 18 & I & 0.718 & 1.000 \\
\hline Educational status & & & & 12.687 & 0.005 \\
\hline Primary education & 0 & 87 & 8 & & \\
\hline High school & I & 48 & 2 & & \\
\hline Higher education & 2 & 7 & 2 & & \\
\hline Marital status & & & & 0.817 & 1.000 \\
\hline Married & 3 & 137 & 12 & & \\
\hline Divorced/Widowed & 0 & 5 & 0 & & \\
\hline PSA (ng/mL) & $2.73 \pm 1.38$ & $2.85 \pm 1.28$ & $2.18 \pm 0.81$ & 1.557 & 0.214 \\
\hline Prostate volume $(\mathrm{mL})$ & $63.67 \pm 17.20$ & $67.03 \pm 33.69$ & $62.24 \pm 23.65$ & 0.129 & 0.879 \\
\hline Depression & $1.67 \pm 0.58$ & $3.67 \pm 1.48$ & $6.50 \pm 3.21$ & 18.874 & $0.000 *$ \\
\hline Duration of LUTS (month) & $|2.67 \pm 3.2|$ & $|5.2| \pm 3.73$ & $20.42 \pm 4.25$ & 11.477 & $0.000 *$ \\
\hline \multicolumn{6}{|l|}{ Illness perceptions } \\
\hline Consequences & $1.67 \pm 0.57$ & $4.24 \pm 1.38$ & $6.08 \pm 2.07$ & 14.392 & $0.000 *$ \\
\hline Timeline & $2.67 \pm 0.58$ & $3.89 \pm 1.05$ & $5.25 \pm 0.87$ & 12.145 & $0.000 *$ \\
\hline Personal control & $5.00 \pm 0.00$ & $3.63 \pm 1.07$ & $2.58 \pm 0.67$ & 8.469 & $0.000 *$ \\
\hline Treatment control & $5.67 \pm 1.15$ & $4.62 \pm 1.20$ & $3.17 \pm 1.27$ & 9.401 & $0.000 *$ \\
\hline Identity & $3.00 \pm 0.00$ & $3.90 \pm 1.35$ & $5.92 \pm \mid .31$ & 13.382 & $0.000 *$ \\
\hline Concern & $2.67 \pm 0.58$ & $4.31 \pm 1.26$ & $5.92 \pm 1.68$ & 11.363 & $0.000 *$ \\
\hline Coherence & $6.33 \pm 0.58$ & $4.00 \pm 1.06$ & $2.75 \pm 1.14$ & $|5.44|$ & $0.000 *$ \\
\hline Emotions & $2.33 \pm 0.58$ & $3.96 \pm 1.32$ & $5.92 \pm 1.68$ & 14.248 & $0.000 *$ \\
\hline Total score of IP & $29.33 \pm 0.58$ & $32.55 \pm 3.66$ & $37.58 \pm 4.81$ & 11.453 & $0.000 *$ \\
\hline
\end{tabular}

Note: $* \mathrm{P}<0.001$ (2-tailed).

Abbreviations: LUTS, lower urinary tract symptoms; IP, illness perceptions.

Table 4 Intercorrelations Between Chinese B-IPQ Subscales Among BPH Patients

\begin{tabular}{|c|c|c|c|c|c|c|c|c|c|}
\hline B-IPQ & Mean士SD & $\mathbf{I}$ & 2 & 3 & 4 & 5 & 6 & 7 & 8 \\
\hline Consequences & $4.331 \pm 1.554$ & I & & & & & & & \\
\hline Timeline & $3.968 \pm 1.100$ & $0.707^{*}$ & I & & & & & & \\
\hline Personal control & $3.573 \pm 1.087$ & $-0.705^{*}$ & $-0.612^{*}$ & I & & & & & \\
\hline Treatment control & $4.529 \pm 1.269$ & $-0.753^{*}$ & $-0.654^{*}$ & $0.676^{*}$ & 1 & & & & \\
\hline Identity & $4.038 \pm 1.445$ & $0.839 *$ & $0.718^{*}$ & $-0.634 *$ & $-0.724 *$ & I & & & \\
\hline Concern & $4.40 I \pm 1.372$ & $0.860^{*}$ & $0.722 *$ & $-0.67 I^{*}$ & $-0.756 *$ & $0.797^{*}$ & 1 & & \\
\hline Coherence & $3.949 \pm 1.153$ & $-0.745^{*}$ & $-0.628 *$ & $0.637^{*}$ & $0.67 I^{*}$ & $-0.64 I^{*}$ & $-0.704 *$ & I & \\
\hline Emotions & $4.082 \pm 1.454$ & $0.856^{*}$ & $0.69 I^{*}$ & $-0.707^{*}$ & $-0.774 *$ & $0.840 *$ & $0.883^{*}$ & $-0.73 I^{*}$ & I \\
\hline
\end{tabular}

Notes: I=consequences, $2=$ timeline, $3=$ personal control, $4=$ treatment control, $5=$ identity, $6=$ concern, $7=$ understanding, $8=$ emotional representation. $* \mathrm{P}<0.0 \mathrm{I}(2$-tailed).

\section{The Effect of IPs on Depressive Symptoms Among BPH Patients with LUTS}

A hierarchical regression analysis was conducted to determine the factors associated with depressive symptoms among BPH patients with LUTS. In step 1, the severity and duration of LUTS was significantly and positively associated with depressive symptoms, and explained $47.5 \%$ of the variance in depressive symptoms $\left(F=69.774, \mathrm{R}^{2}=0.475\right.$, 
Table 5 Correlation Between Illness Perception, LUTS, and Depressive Symptoms

\begin{tabular}{|c|c|c|c|c|c|c|c|c|}
\hline Variables & Consequences & Timeline & $\begin{array}{l}\text { Personal } \\
\text { Control }\end{array}$ & $\begin{array}{l}\text { Treatment } \\
\text { Control }\end{array}$ & Identity & Concern & $\begin{array}{l}\text { Illness } \\
\text { Coherence }\end{array}$ & Emotions \\
\hline LUTS & $0.528^{*}$ & $0.417^{*}$ & $-0.464 *$ & $-0.473 *$ & $0.457^{*}$ & $0.479 *$ & $-0.525^{*}$ & $0.512^{*}$ \\
\hline LUTS timeline (month) & $0.622^{*}$ & $0.739 *$ & $-0.508^{*}$ & $-0.568 *$ & $0.606 *$ & $0.554 *$ & $-0.462 *$ & $0.573 *$ \\
\hline Depressive symptoms & $0.875^{*}$ & $0.668^{*}$ & $-0.647^{*}$ & $-0.715^{*}$ & $0.779 *$ & $0.87 I^{*}$ & $-0.70 I^{*}$ & $0.878 *$ \\
\hline
\end{tabular}

Note: $* \mathrm{P}<0.01$ (2-tailed).

Abbreviation: LUTS, lower urinary tract symptoms.

Table 6 Correlations Between Depression Illness Perception Variables and Personal Characteristics

\begin{tabular}{|l|r|r|r|r|r|r|r|r|r|}
\hline Variables & Consequences & Timeline & $\begin{array}{l}\text { Personal } \\
\text { Control }\end{array}$ & $\begin{array}{l}\text { Treatment } \\
\text { Control }\end{array}$ & Identity & Concern & $\begin{array}{l}\text { IIIness } \\
\text { Coherence }\end{array}$ & Emotions & Depression \\
\hline Age & 0.095 & 0.151 & -0.132 & -0.122 & $0.177^{*}$ & 0.130 & -0.129 & 0.154 \\
BMI & -0.013 & -0.080 & 0.060 & -0.025 & -0.103 & -0.055 & -0.001 & -0.010 & 0.128 \\
Education & $-0.400 * * *$ & $-0.282 * * *$ & $0.299 * * *$ & $0.27 I^{* * *}$ & $-0.24 I^{* *}$ & $-0.35 I^{* * *}$ & $0.497 * * *$ & $-0.304^{* * *}$ & $-0.339 * * *$ \\
Current smoker & 0.040 & 0.088 & -0.015 & 0.008 & 0.027 & 0.013 & 0.021 & -0.025 & 0.052 \\
Alcohol use & 0.023 & 0.140 & 0.016 & -0.027 & 0.034 & 0.018 & 0.002 & -0.010 & 0.029 \\
Marital status & 0.004 & 0.067 & -0.10 & -0.014 & -0.033 & 0.113 & 0.023 & 0.083 & 0.030 \\
PSA (ng/mL) & 0.081 & 0.064 & -0.036 & -0.041 & 0.063 & 0.051 & -0.002 & 0.065 & 0.031 \\
PV (mL) & -0.052 & 0.063 & -0.081 & 0.030 & -0.043 & -0.088 & 0.049 & -0.057 & -0.094 \\
\hline
\end{tabular}

Note: Values are the correlation coefficients; $* \mathrm{P}<0.05$ (2-tailed), ${ }^{*} * \mathrm{P}<0.01$ (2-tailed), $* * * \mathrm{P}<0.00 \mathrm{I}$ (2-tailed).

Abbreviation: PV, prostate volume.

$\left.\Delta \mathrm{R}^{2}=0.475, \mathrm{P}<0.001\right)$. In step 2 , the severity of LUTS and the negative IPs, including consequences, concern and emotions, were significantly and positively associated with depressive symptoms, and explained $85.1 \%$ of the variance $\left(\mathrm{F}=46.131, \mathrm{R}^{2}=0.851, \Delta \mathrm{R}^{2}=0.376, \mathrm{P}<0.05\right)$, also explained a further $37.6 \%$ of the variance in depressive symptoms. Hence, the negative IPs, including consequences, concern and emotions may act as partial mediator in the association between LUTS and depressive symptoms (see Table 7).

Table 7 The Hierarchical Regression Analyses of Factors Related to Depressive Symptoms of the BPH Patients with LUTS

\begin{tabular}{|c|c|c|c|c|c|c|c|c|}
\hline \multirow[t]{2}{*}{ Variables } & \multicolumn{4}{|l|}{ Step I } & \multicolumn{4}{|l|}{ Step2 } \\
\hline & B & $\boldsymbol{\beta}$ & $\mathbf{t}$ & $p$ & B & $\boldsymbol{\beta}$ & $\mathbf{t}$ & $p$ \\
\hline Constant & -2.042 & & -4.002 & $0.000^{* *}$ & -2.862 & & -3.091 & $0.002^{* *}$ \\
\hline Consequences & & & & & 0.425 & 0.360 & 4.455 & $0.000 * * *$ \\
\hline Timeline & & & & & -0.083 & -0.050 & -0.823 & 0.412 \\
\hline Personal control & & & & & 0.089 & 0.053 & 1.074 & 0.284 \\
\hline Treatment control & & & & & 0.068 & 0.047 & 0.836 & 0.404 \\
\hline Identity & & & & & -0.079 & -0.063 & -0.915 & 0.362 \\
\hline Concern & & & & & 0.403 & 0.302 & 3.819 & $0.000 * * *$ \\
\hline Coherence & & & & & -0.001 & -0.000 & -0.008 & 0.994 \\
\hline Emotions & & & & & 0.467 & 0.370 & 4.402 & $0.000 * * *$ \\
\hline LUTS & 0.194 & 0.386 & 6.143 & $0.000 * * *$ & 0.047 & 0.093 & 2.379 & $0.019 *$ \\
\hline LUTS timeline (month) & 0.204 & 0.446 & 7.104 & $0.000 * * *$ & 0.036 & 0.079 & 1.569 & 0.119 \\
\hline $\mathrm{F}$ & 69.774 & & & $0.000 * * *$ & 46.131 & & & $0.000 * * *$ \\
\hline $\mathrm{R}^{2}$ & 0.475 & & & & 0.851 & & & \\
\hline${ }^{\Delta} R^{2}$ & 0.475 & & & & 0.376 & & & \\
\hline
\end{tabular}

Note: $*<0.01, * *<0.01, * * *<0.001$.

Abbreviation: LUTS, lower urinary tract symptom. 


\section{Discussion}

The present study aimed at investigating whether LUTS is associated with depressive symptoms and whether IPs mediate the correlation between LUTS and depressive symptoms. The results of correlation analysis indicated a strong correlation between IPs, depressive symptoms and LUTS among BPH patients. Moreover, the mediation analysis demonstrated that the IPs may mediate the relationship between the severity of depressive symptoms and LUTS among BPH patients.

Several longitudinal follow-up studies evaluated the impact of BPH on the risk of developing depression. The prospective study conducted by Chung et al found that the presence of moderate-to-severe LUTS measured by the IPSS at baseline were significantly associated with an increased risk of depression measured by the Geriatric Depression Scale to assess depression in elderly men at 2-year follow-up. ${ }^{28}$ In addition, the 1-year-longitudinal, population-based investigation conducted by Huang et al found that the likelihood of being diagnosed with depressive disorder was 1.87 times higher in patients with BPH than with matched controls. ${ }^{29}$ The relationship between LUTS and depressive symptoms is complex and has shown a reciprocal or bidirectional relationship. Several studies have demonstrated that LUTS can induce depressive symptoms in patients with BPH. A large, crosssectional, population-based study demonstrated that men with moderate-to-severe depression had a higher odds of LUTS. $^{30}$

There are several mechanisms that account for the relationship between depression and LUTS secondary to $\mathrm{BPH}$, however the direction of causation is not well understood. The pathophysiology of $\mathrm{BPH}$, including chronic inflammatory (eg C-reactive protein, interleukin-6) and genetic mechanism (eg PDE11A gene) may contribute to the depression of patients with BPH/LUTS ${ }^{31-34}$ In the psychology aspect, LUTS can lead to embarrassment, restriction of daily activities and impaired physical state, and discourage sexual activity may also increase odds of depression. ${ }^{35}$ Our correlation analysis showed significantly positive association between the LUTS scores and negative IPs, indicating that with increasing symptom severity the levels of negative IPs also increase. Individuals experienced more disease-related symptoms might generate more negative cognitions and belief of their disease, which are IPs. The current research is consistent with previous studies that the higher disease activity is associated with poorer IPs. ${ }^{36}$ Thoughts of serious consequences of their disease tended to generate greater levels of perceived stress, finally converted into negative psychological distress. ${ }^{37,38}$

Consistent with the past study by Price et al that IPs (eg identity, concern, consequences, personal control, and emotion) were associated with depressive symptom in a population with advanced disease receiving palliative care, however, the causal domain had no impact on depression. ${ }^{39}$ Moreover, our previous study conducted on patients with bladder cancer demonstrated that negative IPs were positively correlated with the severity of depressive symptoms. ${ }^{40}$ Overall, individuals with negative IPs from illness experienced greater levels of perceived stress, which had an impact on the physical and mental health. ${ }^{38}$

The findings of our study are also in line with the body of research demonstrating the mediational role of IPs in depression. According to the CSM theory, individuals may generate different IPs for the same disease depending on their own clinical symptoms. In our study, the relationship between the severity of LUTS and depressive symptoms was mediated by emotional dimension. These findings suggests that negative emotional perceptions may facilitate feelings of hopelessness and sadness. The causal beliefs affected emotional reactions, coping strategies, illness behavior, and comorbid depression. ${ }^{41}$ Interestingly, the consequences and concerns of IPs also mediate the relationship between the severity of LUTS and depressive symptoms. In contrast to our hypothesis, the mediation effect of identity about the illness on the relationship between LUTS and depression was not found. In addition, Yankouskaya et al found that cognitive dimension of IPs, including consequences and identity, mediated the association between symptom activity and pain. ${ }^{42}$ The Common Sense Model can account for the psychological reactions of patients who report being unaware of their cancer diagnosis, and illness coherence mediated the relationship between awareness of a cancer diagnosis and anxiety. ${ }^{43}$ The mediational function of IPs is complex and controversial. The study conducted by Knowles et al provided the evidence that maladaptive coping acted as a strong and significant mediator between IPs and depressive symptoms. ${ }^{44}$ However, the study conducted by Zhang et $\mathrm{al}^{23}$ showed IPs did not have definite direct impact on coping strategies; however, the direct influence of IPs on stress and maladaptive coping were found.

Overall, our findings may provide further evidence for the important mediation effects of IPs on perceived 
depressive symptoms. IPs are modifiable, and maladaptive perceptions can be improved by cognitive behavioral therapy. Cognitive behavioural therapy improved IPs in patients with functional somatic syndromes, thus improving physical health, somatic symptoms and illness worry. ${ }^{45}$ In a randomized controlled trial of patients with IBD, compared with the control group, those who received acceptance and commitment therapy reported greater improvements in perceived stress and depression. ${ }^{46}$ Our results suggest treatments aimed at improving individual IPs may be used by physicians to help BPH patients suffering from LUTS in improving the psychological distress.

The current study had several limitations. First, given the cross-sectional design, the present study was preliminary, and did not verify the direction of causality between the LUTS and depressive symptoms. The study presented a relationship between IPs and LUTS, however, additional factors (eg coping) that may explain the relationship was not assessed. Second, the generalizability of our findings was limited by the small size sample and lack of agematched controls. Third, since the current study lacked a control group and interventions (eg CBT), further study is required to confirm these findings.

Overall, LUTS secondary to BPH induces depressive symptoms in patients, which in turn exacerbates LUTS and results in worsening depression. BPH/LUTS and depressive symptoms may show a reciprocal/bidirectional relationship. This preliminary evidence supports the validity of IPs and highlights the importance of interventions that may break the link between depressive symptoms and LUTS by reducing negative IPs. By identifying which IPs are associated with depression, medical professionals can provide some targeted interventions to focus on these specific areas, which can help BPH patients cope with their illness and improve depressive symptoms.

\section{Ethical Approval}

The current study was approved by the ethics committee of the Second Affiliated Hospital of Anhui Medical University (NO:11MNLL/11). This study was conducted in accordance with the declaration of Helsinki. Written informed consent was obtained from all participants.

\section{Acknowledgments}

We are grateful to all the research assistants for their contributions to the data collection and management, and to all participants who supported and allowed their data to be used in our research.

\section{Funding}

There is no funding to report.

\section{Disclosure}

No potential conflict of interest was reported by the authors.

\section{References}

1. Wang W, Guo Y, Zhang D, et al. The prevalence of benign prostatic hyperplasia in mainland China: evidence from epidemiological surveys. Sci Rep. 2015;5:13546. doi:10.1038/srep13546

2. Wei JT, Calhoun E, Jacobsen SJ. Urologic diseases in America project: benign prostatic hyperplasia. $J$ Urol. 2005;173:1256-1261. doi:10.1097/01.ju.0000155709.37840.fe

3. Koskimäki J, Hakama M, Huhtala $\mathrm{H}$, et al. Association of non-urological diseases with lower urinary tract symptoms. Scand J Urol Nephrol. 2001;35:377-381. doi:10.1080/00365590175322 4431

4. Noguchi N, Chan L, Cumming RG, et al. Lower urinary tract symptoms and incident falls in community dwelling older men: the concord health and ageing in men project. $J$ Urol. 2016;196:1694-1699. doi:10.1016/j.juro.2016.06.085

5. Speakman M, Kirby R, Doyle S, et al. Burden of male lower urinary tract symptoms (LUTS) suggestive of benign prostatic hyperplasia (BPH) - focus on the UK. BJU Int. 2015;115(4):508-519. doi:10. 1111/bju. 12745

6. Wu MP, Huang YT, Wu CY, et al. Depression is a major risk factor for the development of dementia in people with lower urinary tract symptoms: a nationwide population-based study. PLoS One. 2019;14: e0217984. doi:10.1371/journal.pone.0217984

7. Chiang $\mathrm{CH}, \mathrm{Wu} \mathrm{MP}, \mathrm{Ho} \mathrm{CH}$, et al. Lower urinary tract symptoms are associated with increased risk of dementia among the elderly: a nationwide study. Biomed Res Int. 2015;2015:187819. doi:10. $1155 / 2015 / 187819$

8. Maggi M, Gentilucci A, Salciccia S, et al. Psychological impact of different primary treatments for prostate cancer: a critical analysis. Andrologia. 2019;51(1):e13157. doi:10.1111/and.13157

9. Mundle R, Afenya E, Agarwal N. The effectiveness of psychological intervention for depression, anxiety, and distress in prostate cancer: a systematic review of literature. Prostate Cancer Prostatic Dis. 2021;24(3):674-687. doi:10.1038/s41391-021-00342-3

10. Fervaha G, Izard JP, Tripp DA, et al. Depression and prostate cancer: a focused review for the clinician. Urol Oncol. 2019;37(4):282-288. doi:10.1016/j.urolonc.2018.12.020

11. Ayuso-Mateos JL, Vázquez-Barquero JL, Dowrick C, et al. Depressive disorders in Europe: prevalence figures from the ODIN study. Br J Psychiatry. 2001;179:308-316. doi:10.1192/bjp.179.4.308

12. Martin S, Vincent A, Taylor AW, et al. Lower urinary tract symptoms, depression, anxiety and systemic inflammatory factors in men: a population-based cohort study. PLoS One. 2015;10:e137903. doi:10.1371/journal.pone. 0137903

13. Jeong WS, Choi HY, Nam JW, et al. Men with severe lower urinary tract symptoms are at increased risk of depression. Int Neurourol J. 2015;19(4):286-292. doi:10.5213/inj.2015.19.4.286

14. Laumann EO, Kang JH, Glasser DB, et al. Lower urinary tract symptoms are associated with depressive symptoms in white, black and Hispanic men in the United States. J Urol. 2008;180:233-240. doi:10.1016/j.juro.2008.03.055 
15. Leventhal H, Phillips LA, Burns E. The Common-Sense Model of Self-Regulation (CSM): a dynamic framework for understanding illness self-management. $J$ Behav Med. 2016;39:935-946. doi:10.1007/ s10865-016-9782-2

16. Shallcross AJ, Becker DA, Singh A, et al. Illness perceptions mediate the relationship between depression and quality of life in patients with epilepsy. Epilepsia. 2015;56:e186-90. doi:10.1111/epi.13194

17. De Gucht V. Illness perceptions mediate the relationship between bowel symptom severity and health-related quality of life in IBS patients. Qual Life Res. 2015;24:1845-1856. doi:10.1007/s11136015-0932-8

18. Eckhardt MD, van Venrooij GE, Boon TA. Symptoms and quality of life versus age, prostate volume, and urodynamic parameters in 565 strictly selected men with lower urinary tract symptoms suggestive of benign prostatic hyperplasia. Urology. 2001;57:695-700. doi:10. 1016/S0090-4295(00)01101-8

19. Barry MJ, Fowler FJ, O'Leary MP; The Measurement Committee of the American Urological Association. The American Urological Association symptom index for benign prostatic hyperplasia. J Urol. 1992;148(5):1549-57; discussion 1564. doi:10.1016/s00225347(17)36966-5

20. Choi EP, Lam CL, Chin WY. Validation of the International Prostate Symptom Score in Chinese males and females with lower urinary tract symptoms. Health Qual Life Outcomes. 2014;12:1. doi:10.1186/ 1477-7525-12-1

21. Broadbent E, Petrie KJ, Main J, et al. The brief illness perception questionnaire. $J$ Psychosom Res. 2006;60:631-637. doi:10.1016/j. jpsychores.2005.10.020

22. Broadbent E, Wilkes C, Koschwanez H, et al. A systematic review and meta-analysis of the Brief Illness Perception Questionnaire. Psychol Health. 2015;30:1361-1385. doi:10.1080/08870446.2015.1070851

23. Zhang M, Hong L, Zhang T, et al. Illness perceptions and stress: mediators between disease severity and psychological well-being and quality of life among patients with Crohn's disease. Patient Prefer Adherence. 2016;10:2387-2396. doi:10.2147/PPA.S118413

24. Fan SY, Eiser C, Ho MC, et al. Health-related quality of life in patients with hepatocellular carcinoma: the mediation effects of illness perceptions and coping. Psychooncology. 2013;22:1353-1360. doi:10.1002/pon.3146

25. Kroenke K, Spitzer RL, Williams JB. The PHQ-9: validity of a brief depression severity measure. J Gen Intern Med. 2001;16:606-613. doi:10.1046/j.1525-1497.2001.016009606.x

26. Wang W, Bian Q, Zhao Y, et al. Reliability and validity of the Chinese version of the Patient Health Questionnaire (PHQ-9) in the general population. Gen Hosp Psychiatry. 2014;36:539-544. doi:10.1016/j.genhosppsych.2014.05.021

27. Löwe B, Kroenke K, Herzog W, et al. Measuring depression outcome with a brief self-report instrument: sensitivity to change of the Patient Health Questionnaire (PHQ-9). J Affect Disord. 2004;81:61-66. doi:10.1016/S0165-0327(03)00198-8

28. Chung RY, Leung JC, Chan DC, et al. Lower urinary tract symptoms (LUTS) as a risk factor for depressive symptoms in elderly men: results from a large prospective study in Southern Chinese men. PLoS One. 2013;8(9):e76017. doi:10.1371/journal.pone.0076017

29. Huang CY, Chiu KM, Chung SD, et al. Increased risk of depressive disorder following the diagnosis of benign prostatic enlargement one-year follow-up study. J Affect Disord. 2011;135:395-399. doi:10.1016/j.jad.2011.07.001

30. Breyer BN, Kenfield SA, Blaschko SD, et al. The association of lower urinary tract symptoms, depression and suicidal ideation: data from the 2005-2006 and 2007-2008 National Health and Nutrition Examination Survey. J Urol. 2014;191(5):1333-1339. doi:10.1016/j. juro.2013.12.012
31. Miller AH, Maletic V, Raison CL. Inflammation and its discontents: the role of cytokines in the pathophysiology of major depression. Biol Psychiatry. 2009;65(9):732-741. doi:10.1016/j. biopsych.2008.11.029

32. Hung SF, Chung SD, Kuo HC, Gakis G. Increased serum C-reactive protein level is associated with increased storage lower urinary tract symptoms in men with benign prostatic hyperplasia. PLoS One. 2014;9:e85588. doi:10.1371/journal.pone.0085588

33. Dunphy C, Laor L, Te A, et al. Relationship between depression and lower urinary tract symptoms secondary to benign prostatic hyperplasia. Rev Urol. 2015;17:51-57. doi:10.3909/riu0658

34. Wong ML, Whelan F, Deloukas P, et al. Phosphodiesterase genes are associated with susceptibility to major depression and antidepressant treatment response. Proc Natl Acad Sci U S A. 2006;10 3:15124-15129. doi:10.1073/pnas.0602795103

35. Coyne KS, Wein AJ, Tubaro A, et al. The burden of lower urinary tract symptoms: evaluating the effect of LUTS on health-related quality of life, anxiety and depression: EpiLUTS. BJU Int. 2009;103(Suppl 3):4-11. doi:10.1111/j.1464-410X.2009.08371.x

36. Kristoffersen ES, Lundqvist C, Russell MB. Illness perception in people with primary and secondary chronic headache in the general population. J Psychosom Res. 2019;116:83-92. doi:10.1016/j. jpsychores.2018.12.001

37. Krok D, Telka E, Zarzycka B. Illness perception and affective symptoms in gastrointestinal cancer patients: a moderated mediation analysis of meaning in life and coping. Psychooncology. 2019;28: 1728-1734. doi:10.1002/pon.5157

38. Miceli J, Geller D, Tsung A, et al. Illness perceptions and perceived stress in patients with advanced gastrointestinal cancer. Psychooncology. 2019;28:1513-1519. doi:10.1002/pon.5108

39. Price A, Goodwin L, Rayner L, et al. Illness perceptions, adjustment to illness, and depression in a palliative care population. J Pain Symptom Manage. 2012;43:819-832. doi:10.1016/j.jpainsymman.2011.05.013

40. Zhang Z, Yang L, Xie D, et al. Illness perceptions are a potential predictor of psychological distress in patients with non-muscleinvasive bladder cancer: a 12-month prospective, longitudinal, observational study. Psychol Health Med. 2020;25:969-979. doi:10.1080/ 13548506.2019.1707242

41. Rief W, Nanke A, Emmerich J, et al. Causal illness attributions in somatoform disorders: associations with comorbidity and illness behavior. J Psychosom Res. 2004;57:367-371. doi:10.1016/j. jpsychores.2004.02.015

42. Yankouskaya A, Boughey A, McCagh J, et al. Illness perception mediates the relationship between the severity of symptoms and perceived health status in patients with Behçet disease. $J$ Clin Rheumatol. 2019;25:319-324. doi:10.1097/RHU.0000000000000872

43. Chittem M, Norman P, Harris PR. Illness representations and psychological distress in Indian patients with cancer: does being aware of one's cancer diagnosis make a difference? Psychooncology. 2015;24:1694-1700. doi:10.1002/pon.3837

44. Knowles SR, Austin DW, Sivanesan S, et al. Relations between symptom severity, illness perceptions, visceral sensitivity, coping strategies and well-being in irritable bowel syndrome guided by the common sense model of illness. Psychol Health Med. 2017;22:524-534. doi:10.1080/13548506.2016.1168932

45. Christensen SS, Frostholm L, Ørnbøl E, et al. Changes in illness perceptions mediated the effect of cognitive behavioural therapy in severe functional somatic syndromes. $J$ Psychosom Res. 2015;78:363-370. doi:10.1016/j.jpsychores.2014.12.005

46. Wynne B, McHugh L, Gao W, et al. Acceptance and commitment therapy reduces psychological stress in patients with inflammatory bowel diseases. Gastroenterology. 2019;156:935-945.e1. doi:10.10 53/j.gastro.2018.11.030 


\section{Publish your work in this journal}

The International Journal of General Medicine is an international, peer-reviewed open-access journal that focuses on general and internal medicine, pathogenesis, epidemiology, diagnosis, monitoring and treatment protocols. The journal is characterized by the rapid reporting of reviews, original research and clinical studies across all disease areas. The manuscript management system is completely online and includes a very quick and fair peer-review system, which is all easy to use. Visit http://www.dovepress.com/ testimonials.php to read real quotes from published authors.

Submit your manuscript here: https://www.dovepress.com/international-journal-of-general-medicine-journal 